\title{
Epidemiology and RAPD-PCR typing of thermophilic campylobacters from children under five years and chickens in Morogoro Municipality, Tanzania
}

Idrissa S. Chuma ${ }^{1 *}$, Hezron E. Nonga ${ }^{2}$, Robinson H. Mdegela² and Rudovick. R. Kazwala²

\begin{abstract}
Background: Campylobacter species are gram negative and flagellated bacteria under the genus Campylobacter, family Campylobacteriaceae. These pathogens cause zoonotic infections among human and animal populations. This study was undertaken between December 2006 and May 2007 to determine prevalence, risk factors and genetic diversity of thermophilic Campylobacter isolates from children less than 5 years and chickens in Morogoro Municipality, Tanzania.
\end{abstract}

Methods: The Skirrow's protocol was used for isolation and identification of Campylobacter from 268 human stool specimens and 419 chicken cloacal swabs. Patient biodata and risk factors associated with human infection were also collected. Genetic diversity of Campylobacter isolates was determined by a RAPD-PCR technique using OPA 11 primer (5'-CAA TCG CCG T-3'). Phylogenetic analysis and band pattern comparison were done by Bionumerics software and visual inspection.

Results: Stool samples from 268 children and 419 cloacal swabs from chickens were analyzed. Prevalence of thermophilic Campylobacters in children was 19\% with higher isolation frequency $(p=0.046)$ in males (23.5\%) than females (13.8\%). Campylobacter jejuni (78.4\%) was more isolated $(p=0.000)$ than C. coli (19.6\%) and 2\% were unidentified isolates. In chickens, the prevalence was $42.5 \%$ with higher isolation rate $(p=0.000)$ of $C$. jejuni $(87 \%)$ than C. coli (13\%). Campylobacters were more frequently recovered $(p=0.000)$ from indigenous/ local chickens (75. $0 \%)$ followed by cockerels (52.2\%), broilers (50.0\%) and lowest in layers (22.7\%). Keeping chickens without other domestic animals concurrently $(p=0.000)$, chicken types $(p=0.000)$ and flock size $(p=0.007)$ were risk factors for infection in chickens. One hundred and fifty two (152) thermophillic Campylobacter isolates were genotyped by RAPD-PCR of which 114 were C. jejuni (74 from chickens and 40 humans) and 38 C. coli (28 from chickens and 10 humans). Comparison of Campylobacter isolates from children and chickens revealed high diversity with only $6.1 \%$ of C. jejuni and $5.3 \%$ of C. coli being $100 \%$ genetically similar.

Conclusions: This study has recorded high prevalence of thermophilic Campylobacter in children less than 5 years and chickens in Morogoro municipality. The observed genetic similarity among few C. jejuni and C. coli isolates from children and chicken suggests existence of cross transmission of these pathogens between children under 5 years and chickens.

Keywords: Campylobacter jejuni, C. coli, Epidemiology, RAPD PCR, Genetic diversity, Children, Chicken, Morogoro, Tanzania

\footnotetext{
* Correspondence: chumaidr@gmail.com

${ }^{1}$ Tanzania National Parks (Serengeti), P. O. Box 3134, Arusha, Tanzania

Full list of author information is available at the end of the article
} 


\section{Background}

Thermophilic Campylobacters include Campylobacter jejuni, C. coli and C. lari have been causing gastroenteritis, which is a major public health concern worldwide since 1970s [1]. Ecologically, Campylobacter species are ubiquitous and may be isolated from gastrointestinal tract of reservoir animals in particular chicken and other birds [2]. In Tanzania, urban and peri-urban agriculture (UPA) has been expanding with chicken, cattle and pigs being major livestock species kept for meat production; dogs and cats for watching, controlling pests, hunting and as pets. Increasing urbanization with animals living in closer proximity with humans is among risks for transmission of zoonotic diseases including campylobacteriosis. Spread of zoonotic diseases may be enhanced by poor hygiene and sanitation; malnutrition; poor health status; poor feeding habits; poor immunity and HIV and AIDS [3-8]. Thermophilic Campylobacter isolation rates of up to $70 \%$ have been reported in chickens [9], ducks 80\% [10], beef 9.3\% [11], pork 10.6\% [12] and milk 13.4\% (Kashoma, 2015; personal communication). Consumption of raw or undercooked meat, raw milk and untreated water are among predisposing factors to Campylobacter infection in humans [3, 13-16]. These malpractices are not uncommon among people of diverse socio-cultural origins in rural settings of Tanzania. Limited water supply, lack of water treatment and contamination of water with pathogens [17-19] aggravates situation by increasing risks for Campylobacter infection both in human and animal populations.

Several epidemiological studies aimed at isolating thermophilic Campylobacter species, establish their prevalence and risk factors in Tanzania have been conducted in humans, poultry, cattle and water [3, 20, 21]. However, limited studies aimed at establishing the link between infections in humans and animals in Tanzania [3]. The current study was undertaken to positively contribute in bridging this gap of knowledge by exploring genetic relatedness among thermophilic Campylobacter isolates from human and chicken populations in Tanzania. Thus, this study reports prevalence, risk factors and genetic diversity of thermophilic Campylobacter isolates from children less than five years of age and chickens in Morogoro municipality, Tanzania. A simple, fast and cost effective Random amplified polymorphic DNA (RAPD) PCR assay [22] was employed to determine the genetic diversity of thermophilic Campylobacter isolates in this study. This study has enabled us to deduce existence of zoonotic transmissions of these bacteria between children less than 5 years and chicken populations in Morogoro, Tanzania.

\section{Methods}

\section{Study area and sampling}

This cross-sectional study was conducted in Morogoro Municipality, Tanzania $\left(37^{\circ} 4^{\prime} \mathrm{E} ; 4^{\circ} 49^{\prime} \mathrm{S}\right.$ and altitude of
487-600 $\mathrm{m}$ above sea level) between December 2006 and May 2007. Aim of the current study was to determine the prevalence, risk factors for infection and genetic relatedness among thermophilic Campylobacter isolates from children below 5 years of age and chickens. Sample sizes were calculated using the formula $n=Z^{2} p$ $(1-p) / d^{2}$ [23] where: $n$ is sample size; $Z$ is the multiplier from the normal distribution, $p$ is the expected prevalence and $d$ is the desired absolute precision. The expected prevalence of campylobacter infection $(p)$ used for sample size estimation was $p=20 \%$ for humans [24] and $p=70 \%$ for chickens [25]. Other values $(Z, d$, and CI) were kept constant. With $Z$ value of 1.96 at $95 \%$ confidence interval $(\mathrm{CI})$ and desired precision $(d)$ of 0.05 , the calculated minimum sample sizes $(n)$ were 250 and 330 for humans and chickens, respectively.

Children under 5 years of age attending Outpatient Department (OPD) at Morogoro Regional and Mazimbu Hospitals, Mafiga, Madizini, Usangi and Upendo health facilities were enrolled in this study. Children that were admitted, hospitalized and those under antibiotic therapy were excluded to avoid confounding effects on the bacterial isolation. Human stool samples were collected in clean sterile $10 \mathrm{ml}$-plastic containers by parents/guardians and submitted to the medical laboratory technicians. The samples were aseptically transferred into sterile 10 ml-universal bottles containing $5 \mathrm{ml}$ of Campylobacter enrichment broth and stored at $4{ }^{\circ} \mathrm{C}$ before and during shipment to the laboratory. Biodata and the possible risk factors associated with human infection (age, sex, keeping chickens, keeping other animals and boiling or treating drinking water) were recorded. History of the study children experiencing a gastrointestinal disorder characterized by passing out loose and watery stool at least three times a day in the past 2 weeks and consistency of the stool samples were the criteria used to categorize the patients as diarrhoeic or non-diarrhoeic.

Chicken cloacal swab samples were collected from 22 chicken flocks/farms located in various areas within Morogoro Municipality. After collection, the swabs were put into universal bottles containing $5 \mathrm{ml}$ of Campylobacter Enrichment Broth (Oxoid Ltd, Basingstoke, Hampshire, England). These samples were placed on ice blocks in a cool box at approximate temperature of $4{ }^{\circ} \mathrm{C}$ and transported to the laboratory within $2 \mathrm{~h}$. Study chicken populations included indigenous/local chickens, broilers, layers and cockerels. Categories of chickens sampled are in line with types preferably kept by majority of farmers/livestock keepers in Morogoro municipality, Tanzania. These were: indigenous/local chickens are of mixed sexes and free ranging while broilers are chickens of mixed sexes kept for meat production. On the other hand, layers are all females kept for egg production and cockerels are all males kept for dual purposes 
namely meat and reproduction. The chickens were samples from 22 different flocks/farms located in various areas within Morogoro municipality. Among the indigenous/ local chickens were those at the Morogoro Central Market ready for sale. For convenience, the flocks were classified as small when number of chickens of the chickens was categorized as 1 to 199, medium (200-299) and large (300 and above up to 7000). Age groups of the chickens were assigned as $0-4,5-9,10-14,15-19$ and 20 weeks and above $(20+)$. It is worthwhile to note that age of 49 chickens could not be ascertained due to lack of proper record keeping and these were excluded in age related analysis. In addition, chickens less than 3 weeks of age and those under treatment with antibiotics were excluded to avoid confounding effects of the maternal immunity and negative growth of Campylobacter on the media, respectively. For convenience, flocks with 199 chickens and less were classified as small, those with 200-299 chickens as medium and flocks/farms with 300 and/ more as large. Information on chicken types, flock size, age and keeping of other animals was obtained by field observations and confirmed in interviews with the owners.

\section{Bacterial isolation and identification}

Campylobacter species are relatively slow-growing, fastidious bacteria that require specialized culture conditions; hence, they grow best under reduced oxygen tension on nutritional basal media supplemented with $5-10 \%$ blood. In the laboratory, human stool samples and chicken cloacal swabs were aseptically inoculated in $10 \mathrm{ml}$-universal bottles containing $5 \mathrm{ml}$ of Campylobacter Enrichment Broth (Lab M, International Diagnostics Group, plc, Lancashire, UK). The bottles were incubated at $37^{\circ} \mathrm{C}$ for $24 \mathrm{~h}$ in an incubator (Heraeus B5050, Germany). Thereafter, one loopful of the enriched human or chicken samples was plated onto modified cefoperazone charcoal deoxychocolate agar (mCCDA) (Oxoid Ltd, Basingstoke, Hampshire, England) supplemented with CCDA selective supplement (Oxoid Ltd, Basingstoke, Hampshire, England). The plates were put in an anaerobic jar (Coldstream Engeneering Ltd, 18-10, Arista, Sweden) with microaerophilic environments generated by a lighted candle and then in the incubator (Memmert, Germany) at $43{ }^{\circ} \mathrm{C}$ for $48 \mathrm{~h}$. Bacterial colonies suspected to be thermophilic campylobacter species based on growth at $43{ }^{\circ} \mathrm{C}$ and colony morphology were subjected to further examination by microscopy using Gram's staining, motility and biochemical tests using Skirrow's protocol as previously described [3]. Confirmed thermophilic Campylobacter isolates were sub-cultured on mCCDA (Oxoid Ltd, Basingstoke, Hampshire, England) and three loopfuls of 48-h old colonies were harvested and transferred into cryogenic vials (Nalgene ${ }^{\circ}$, Nalge Nunc Int. Corp, USA) containing $1 \mathrm{ml}$ of brain heart infusion broth (Oxoid Ltd, Basingstoke,
Hampshire, England) with 20-30\% glycerol (v/v). The vials were incubated at $37{ }^{\circ} \mathrm{C}$ for $24 \mathrm{~h}$, initially stored at $-20{ }^{\circ} \mathrm{C}$ for $24 \mathrm{~h}$ and then transferred to $-80{ }^{\circ} \mathrm{C}$ until when further analysis by RAPD-PCR genotyping was performed.

\section{RAPD-PCR genotyping}

A total of 152 Campylobacter isolates were genotyped by RAPD-PCR using OPA 11 primer ( $5^{\prime}$-CAA TCG CCG T-3') as described by Miwa et al. [7] and their genetic relatedness compared. Of these, 74 C. jejuni and 28 C. coli were isolated from chickens and 50 (40 C. jejuni and 10 C. coli) from humans. The DNA templates were prepared as described by Miwa et al. [7]. The RAPD reaction mixture consisted of $50 \mathrm{mM} \mathrm{KCl,} 10 \mathrm{mM}$ Tris$\mathrm{HCl}\left(\mathrm{pH} 8.4\right.$ at $\left.25^{\circ} \mathrm{C}\right), 2.5 \mathrm{mM} \mathrm{MgCl}_{2}, 0.1 \%$ Triton X-100, a $200 \mu \mathrm{M}$ concentration of each deoxynucleoside triphosphate, $0.3 \mu \mathrm{M}$ of the primer, $2.5 \mathrm{U}$ of Taq DNA polymerase (Invitrogen), $2.5 \mu \mathrm{l}$ of the template DNA, and sterile nuclease-free water to a final volume of $25 \mu \mathrm{l}$. The $25 \mu \mathrm{l}$ of reaction mixture was cycled in a Mastercycler (Eppendorf ${ }^{\circ}$, Germany) through the following temperature profile: an initial denaturation step at $94{ }^{\circ} \mathrm{C}$ for $1 \mathrm{~min}$; 45 cycles of $94{ }^{\circ} \mathrm{C}$ for $1 \mathrm{~min}, 36{ }^{\circ} \mathrm{C}$ for $1 \mathrm{~min}$, and $72{ }^{\circ} \mathrm{C}$ for $2 \mathrm{~min}$; and a final elongation step at $72{ }^{\circ} \mathrm{C}$ for $5 \mathrm{~min}$. The PCR products were held at $4{ }^{\circ} \mathrm{C}$ until when electrophoresis was performed.

\section{Gel electrophoresis and interpretation}

Five microliter of amplified DNA fragments were electrophoresed alongside $3 \mu \mathrm{l}$ of $1-\mathrm{kb}$ ladder (Promega, Madison, USA) through $1 \%(\mathrm{w} / \mathrm{v})$ agarose gels (Molecular grade - low EEO, Whitehead Scientific (Pty) Ltd) in $1 \mathrm{X}$ TBE buffer (0.45 M Tris, 0.44 M Boric acid and 0.01 M EDTA) (SIGMA ${ }^{\circ}$, Sigma Chemical Co., St Louis, USA). The agarose gels were electrophoresed at $60 \mathrm{~V}$ for $90 \mathrm{~min}$, stained with ethidium bromide (Promega, Madison, USA) $0.005 \%(\mathrm{v} / \mathrm{v})$ and photographed using a computerized image capturing machine, Kodak $4000^{\circ}$.

\section{Statistical analysis}

Data were stored in a Microsoft Office Access database and analyzed using Epi-Info software [26]. Comparison of dichotomous variables was done using Chi-square $\left(x^{2}\right)$ test at a critical probability of 0.05 and $95 \%$ confidence interval. Gel images were imported to BioNumerics version 4.61 computer software (Applied Maths) for analysis and dendrogram production. Pairwise comparisons were accomplished using the Dice similarity coefficient, and the dendrograms were created using the unweighted pair group method using a geometric average (UPGMA). For the whole dataset, the most appropriate optimization and position tolerance settings, as determined by the software, were 0 and $1 \%$, respectively. As the gel images could not be normalized, visual 
inspection was done to determine similarity of the RAPD profiles and their proportions expressed as percentage of the total number of C. jejuni and C. coli isolates analyzed.

\section{Results}

\section{Thermophilic Campylobacter infection in children}

Table 1 summarizes results for thermophilic campylobacter infection in children less than 5 years in Morogoro municipality, Tanzania. A total of 268 stool samples from children less than 5 years were analyzed of which $54 \%(\mathrm{n}=145)$ were males and $46 \%(\mathrm{n}=123)$ females. Prevalence of thermophilic Campylobacter infection was $19.0 \%$ with higher isolation frequency $(p=0.000)$ of Campylobacter jejuni (78.4\%) than C. coli (19.6\%), C. lari was not found and about $2 \%(\mathrm{n}=1)$ could not be identified. Higher prevalence $(p=0.046)$ was observed in males $(23.5 \%)$ than females $(13.8 \%)$.

Prevalence of Campylobacter infection in non-diarrhoeic children (21.6\%) and diarrhoeic (12.8\%) was comparable $(p=0.098)$. Fig. 1 shows higher frequency of isolation $(p=0.048)$ of thermophilic Campylobacters in children originating from densely populated localities namely Sabasaba (40.0\%), Modecco (38.5\%) and Kiwanja cha ndege (K/ndege) (28.0\%) while their counterparts from less populated areas including Bigwa, Kihonda, Kilakala and Mafiga (which is an exception in this case) had relatively lower frequencies $(<12.0 \%$ each).

\section{Thermophilic Campylobacter infection in chickens}

A total of 419 chicken cloacal swabs were collected from 22 chicken flocks located in different areas within Morogoro Municipality. Thirty seven percent (37\%) of samples were obtained from broilers, $42.0 \%$ layers, $15.3 \%$ indigenous and 5.5\% cockerels. Prevalence of thermophilic campylobacter infection in chickens was $42.5 \%$ (Table 2).

Comparison of proportions of the isolated species $(p=0.000)$ revealed that $C$. jejuni was the most predominant species $(87.1 \%)$ followed by C. coli $(12.9 \%)$ and $C$. lari was, again, not found. Higher isolation frequency $(p=0.000)$ was observed in indigenous chickens (75.0\%) than cockerels (52.2\%), broilers (50.0\%) and layers (22.7\%). Risk factors for Campylobacter infection showed that larger and medium sized flocks had higher isolation frequencies of $51.2 \%$ and $37.7 \%$ respectively as compared to medium flocks that had no isolates $(p=0.007)$. Other risks $(p=0.000)$ were keeping: chickens alone (57.6\%) not concurrently

Table 1 Risk factors and isolation frequency of thermophilic campylobacters in children $<5$ years in Morogoro

\begin{tabular}{|c|c|c|c|c|c|c|}
\hline Risk factor & Group & $\begin{array}{l}\text { Number of } \\
\text { children/ chickens }\end{array}$ & Number of cases & $\begin{array}{l}\text { Isolation } \\
\text { frequency (\%) }\end{array}$ & $P$-value & Remarks \\
\hline \multirow[t]{5}{*}{ Age (months) } & $3-13$ & 51 & 7 & 13.7 & $p=0.953$ & NS \\
\hline & $13-24$ & 89 & 19 & 21.4 & & \\
\hline & $25-36$ & 54 & 12 & 22.2 & & \\
\hline & $37-48$ & 41 & 8 & 19.5 & & \\
\hline & $49-60$ & 33 & 5 & 15.2 & & \\
\hline \multirow[t]{2}{*}{ Sex } & Female & 123 & 17 & 13.8 & $p=0.046$ & $S$ \\
\hline & Male & 145 & 34 & 23.5 & & \\
\hline \multirow[t]{3}{*}{ Keeping chickens } & At home & 84 & 10 & 11.9 & $p=0.129$ & NS \\
\hline & At neighbourhood & 58 & 14 & 24.1 & & \\
\hline & Not at all & 126 & 27 & 21.4 & & \\
\hline \multirow[t]{2}{*}{ Keeping other animals } & Kept & 88 & 15 & 17.1 & $p=0.496$ & NS \\
\hline & Not kept & 180 & 37 & 20.5 & & \\
\hline \multirow[t]{2}{*}{ Boiling/treating drinking water } & Boiled/treated & 161 & 27 & 16.7 & $p=0.249$ & NS \\
\hline & Unboiled/untreated & 107 & 24 & 22.4 & & \\
\hline \multirow[t]{2}{*}{ Diarrhoea } & Diarrhoeic & 78 & 10 & 12.8 & $p=0.066$ & NS \\
\hline & Non-diarrhoeic & 190 & 41 & 21.6 & & \\
\hline \multirow[t]{5}{*}{ Thermophilic Campylobacter isolates } & C. jejuni & 51 & 40 & 78.4 & $p=0.000$ & $S$ \\
\hline & C. coli & 51 & 10 & 19.6 & & \\
\hline & C. lari & 51 & 0 & 0.0 & & \\
\hline & Unidentified & 51 & 1 & 2.0 & & \\
\hline & Overall & 268 & 51 & 19.0 & & \\
\hline
\end{tabular}




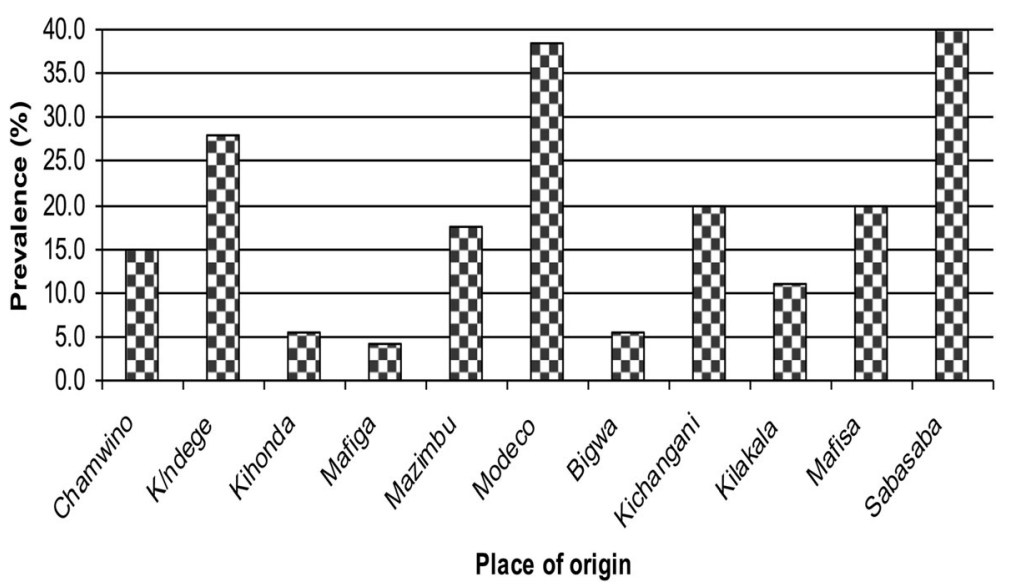

Fig. 1 Isolation frequency and origin of children infected with thermophilic campylobacters in Morogoro

with other domestic animals (31.4\%), indigenous/ local chickens $(75.0 \%)$ than cockerels $(52.2 \%)$, broilers $(50.0 \%)$ and layers $(22.7 \%)$.

\section{Genetic diversity of thermophilic Campylobacter isolates} Of all 152 Campylobacter isolates genotyped by RAPDPCR, 114 were C. jejuni (74 from chickens and 40 humans) and 38 C. coli (28 from chickens and 10 humans). All the isolates successfully generated bands whose patterns were analyzed (Figs. 2 and 3); however,
P29 yielded no bands and was not included in the analysis. C. jejuni isolates were grouped into 28 clusters at $85 \%$ homology each with one to seven individuals. The clusters could not be linked to the geographical origins of the samples. C. jejuni and C. coli from both children and chickens were genetically highly diverse and not host-specific. Seven $C$. jejuni isolates $(6.1 \%)$ and two $C$. coli isolates (5.3\%) from the children and chickens had comparatively similar band patterns. The isolates and their origins in brackets were: C156 (Mazimbu) and H54

Table 2 Risk factors and isolation frequency of thermophilic campylobacters in chickens in Morogoro

\begin{tabular}{|c|c|c|c|c|c|c|}
\hline Risk factor & Group & $\begin{array}{l}\text { Number of } \\
\text { children/chickens }\end{array}$ & Number of cases & $\begin{array}{l}\text { Isolation } \\
\text { frequency (\%) }\end{array}$ & $P$-value & Remarks \\
\hline \multirow[t]{4}{*}{ Chicken types } & Broilers & 156 & 78 & 50.0 & $p=0.000$ & S \\
\hline & Cockerels & 23 & 12 & 52.2 & & \\
\hline & Indigenous & 64 & 48 & 75.0 & & \\
\hline & Layers & 176 & 40 & 22.7 & & \\
\hline \multirow[t]{3}{*}{ Flock size } & Small & 199 & 75 & 37.7 & $P=0.007$ & S \\
\hline & Medium & 19 & 0 & 0.0 & & \\
\hline & Large & 201 & 103 & 51.2 & & \\
\hline \multirow[t]{2}{*}{ Keeping other animals concurrently } & Kept & 242 & 76 & 31.4 & $P=0.000$ & S \\
\hline & Not kept & 177 & 102 & 57.6 & & \\
\hline \multirow[t]{5}{*}{ Age $^{a}$ (weeks) } & $0-4$ & 11 & 3 & 27.3 & $P=0.179$ & NS \\
\hline & $5-9$ & 48 & 7 & 14.6 & & \\
\hline & $10-14$ & 28 & 6 & 21.4 & & \\
\hline & $15-19$ & 93 & 62 & 66.7 & & \\
\hline & $20+$ & 190 & 56 & 29.5 & & \\
\hline \multirow[t]{4}{*}{ Thermophilic Campylobacter isolates } & C. jejuni & 178 & 155 & 87.1 & $p=0.000$ & S \\
\hline & C. coli & 178 & 23 & 12.9 & & \\
\hline & C. lari & 178 & 0 & 0.0 & & \\
\hline & Overall & 419 & 178 & 42.5 & & \\
\hline
\end{tabular}




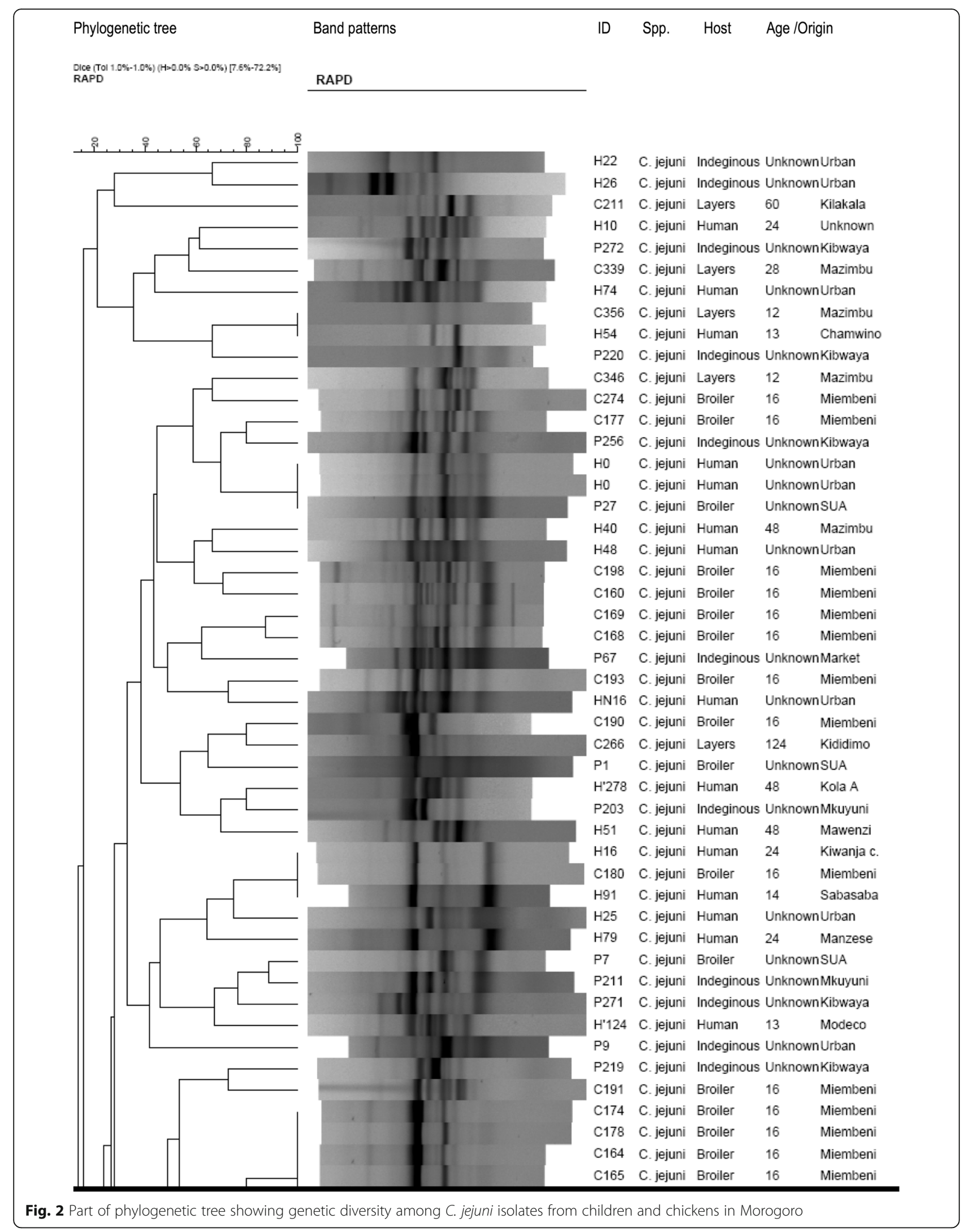




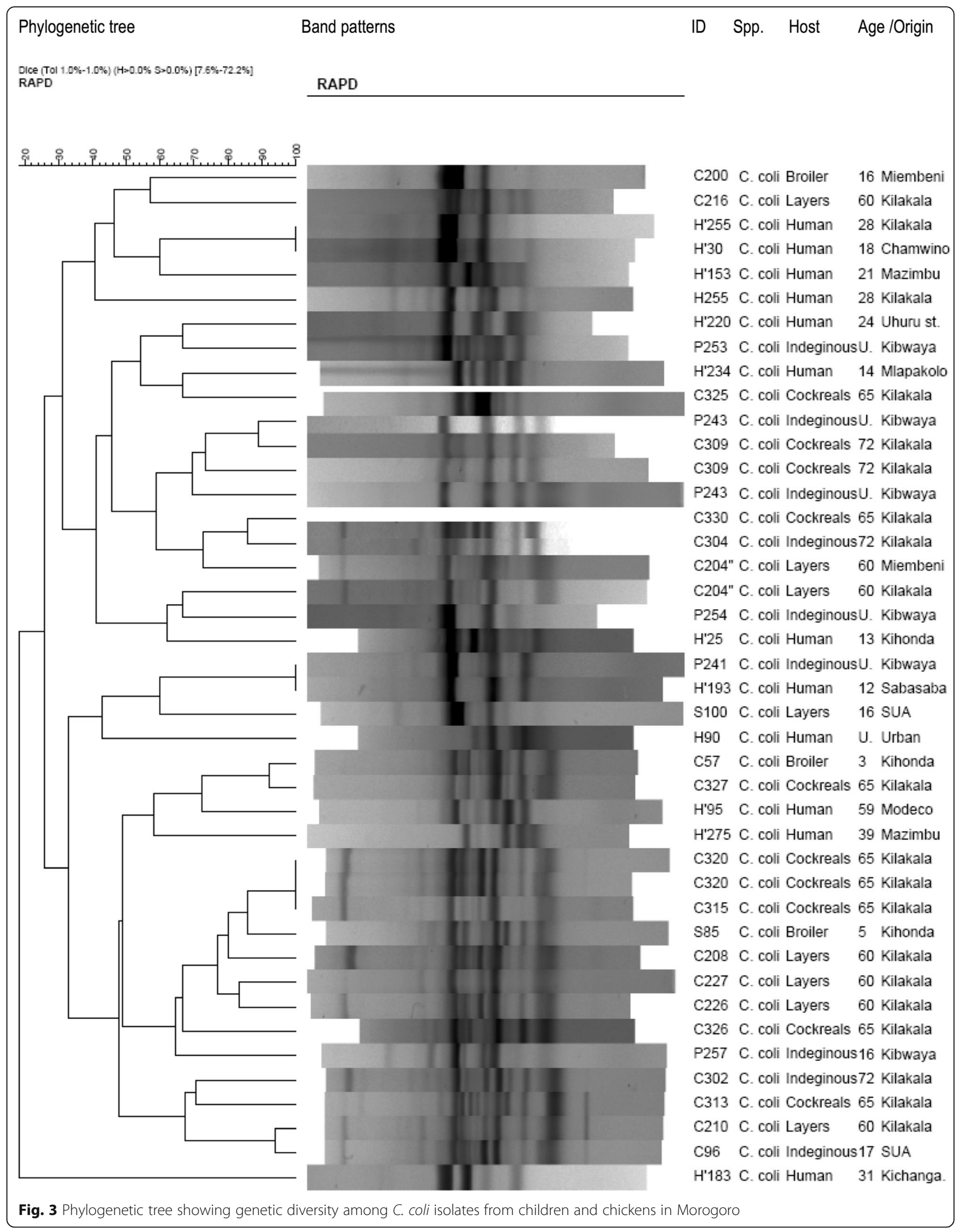


(Chamwino); H0 (Urban) and P27 (SUA); H16 (Kiwanja cha ndege), H91 (Sabasaba) and C180 (Miembeni) for C. jejuni and P241 from Kibwaya and H'193 from Sabasaba for $C$. coli. This finding implies probable sharing of these pathogens between humans and chickens. RAPD PCR was sensitive enough to identify some C. jejuni (C174, C178, C164, C165) and C. coli (C320 and 315) isolates from same flocks with $100 \%$ similarity. Four human $C$. jejuni isolates (H13, H91, H255 and $\mathrm{H} 30$ ) and two C. coli isolates H255 and H30) from different geographical locations were also $100 \%$ similar. It is worthwhile to note that five out of 114 C. jejuni (P216, P104, H0, H21 and H14) and four of 38 C. coli (P243, C309, C320, and C204) were run in duplicates (pairs) and they generated the same band patterns. Eight C. jejuni and C. coli isolates (7\% of all 114 isolates) that came from different geographical origins were $100 \%$ similar. The similarity was observed among four C. jejuni and four C. coli (C191 and H234; C183 and S100; C163, C186, H255 and H30).

\section{Discussion}

Diseases characterized by diarrhoea cause high mortalities in children under the age of five, old people above 65 years and immunocompromised individuals in Tanzania [27]. Children below 5 years and the young are more affected by Campylobacter enteritis than adults $(3,22]$. Preponderance of infection in younger children could be due to poor hygiene and sanitation, malnutrition, intimacy to animals, health status, feeding habits and poor immunity $[3-6,8,28,29]$. In other studies, keeping animals in close proximity with humans was a risk factor for children infection. For example, it was previously reported [8] that children from families that kept poultry and cattle had significantly higher prevalence of Campylobacter infections (27.2\%) than their counterparts without animals (3.4\%). Previous studies also demonstrated that toddlers in families keeping chickens had an average of 4 faeces-to-mouth episodes in 12-h [24]. The fact that poultry faeces can yield viable $C$. jejuni for at least $48 \mathrm{~h}$ after deposition suggests existence of a high risk of Campylobacter transmission in environments where there may be frequent human-animal contacts [29]. In the current study, keeping of chickens or other animals had no influence on infection of children. Therefore, this could be concluded that presence of animals coupled with poor hygiene and interaction between humans and animals is the risk factor for Campylobacter infection rather than a mere keeping of animals.

The prevalence of Campylobacter infection in children observed in this study (19\%) is comparable to $18 \%$ reported in children less than 5 years in Dar es Salaam, Tanzania [30]. Comparable prevalence of Campylobacter infections in children less than 5 years reported elsewhere in the world include: 15.3\% in West Bengal [8],
$16.5 \%$ in Nigeria [31], 17.4\% in Bangladesh [32] and 18\% in Lawalpindi and Islamabad [28]. Higher prevalence of C. jejuni than C. coli coupled with low or lack of C. lari isolation was consistently reported in different countries $[1,3,5,9]$. This may be due to differences in mechanisms of pathogenesis between $C$. jejuni and C. coli within the host cells [33]. Campylobacter coli are more readily phagocytosed and killed by peritoneal macrophages than C. jejuni [33]. This may also happen in situ in human cells and may explain the lower severity of infections due to $C$. coli as compared to $C$. jejuni. For example, C. coli were less often associated with bloody diarrhea and symptomatic disease as compared to $C$. jejuni [34]. However, variations in isolation frequencies of microorganisms may reflect actual differences in composition of common Campylobacter species in local environments.

Higher infection rate observed in male compared to female children supports findings by other studies that reported male to female risk ratios of 2:1 [31] and 1.7:1 [28]. However, other studies elsewhere found no difference in terms of sex of the infected people $[3,5]$. In Tanzania, the actual cause of higher prevalence in males than females is yet to be established and further studies are recommended to elucidate sex predisposition to Campylobacter infection.

Higher prevalence of $C$. jejuni in chicken than C. coli and lack of $C$. lari isolation are in agreement with other previous findings $[3,36,37]$. Campylobacter jejuni is reported to behave as a commensal to a wide range of warm-blooded animals including avian hosts despite its being pathogenic to humans $[37,38]$. The prevalence of thermophilic Campylobacter infection of $42.5 \%$ in chickens revealed by the current study is comparable to $47.8 \%$ [8] but by far lower than $70 \%$ reported earlier [25]. Variations in isolation rates may be explained by the actual differences in local prevalence of Campylobacter in a specific region, seasonality, chicken management system, sampling techniques and laboratory methodologies employed. For example, sampling of chicken faeces by using cloacal swabs was found to be less sensitive as compared to the intestinal contents [25]. Similarly, Cape Town protocol was reported to be a superior technique over Skirrow's method in isolation of Campylobacter [39]. In addition, it was established that at a certain stage of colonization process Campylobacter species can only be found in the caecum and they cannot not be shed in faeces [40]. At such a stage, caecum is the best colonization site and not elsewhere.

The current study reports higher prevalence of Campylobacter infection in indigenous local chickens than broilers, layers and cockerels $(P<0.05)$. A number of studies have highlighted the role of poultry, especially chickens in the transmission of Campylobacter to 
humans. Majority of chickens in Tanzania are indigenous and reared under free-range system with no or minimal veterinary attention posing more public health concerns. These chickens do freely move and spread their droppings around homesteads and contaminated environments serve as potential sources of infection to children that prefer playing nearby.

Campylobacter loads are known to increase with age in broilers as previously reported $[4,25,35]$ and levels of up to $1.2 \times 10^{7} \mathrm{c}$.f.u/g have been reported in poultry [36]. Fourweek old chickens had prevalence of $64.3 \%$ but at the age of 39 weeks the levels significantly increased to $93 \%$. Campylobacter are in most cases commensal to the chicken gastrointestinal track, older chickens are likely to have more Campylobacter load because of prolonged exposure. This is caused by interactions with various sources of infection with larger numbers and diverse strains that they come across with as they age predisposing the chickens to infections. In the current study, thermophilic Campylobacter species were isolated from chickens of all age groups and insignificantly higher isolation frequency was observed in chickens aged 15-19 weeks as compared to other age.

The observed highly diverse band patterns imply existence of genetically distinct individuals or strains of $C$. jejuni and C. coli in human and chicken populations in Morogoro Municipality. Genetic diversity is one of several mechanisms that enable pathogens thrive in adverse conditions within the host and/or in the environments giving them ability to colonize multiple animal hosts. This phenomenon is important in perpetuating Campylobacter infections in human and animal populations. Genomic rearrangement and horizontal gene transfer are among various mechanisms that can generate genomic diversity. These adaptive mechanisms could have contributed to the currently observed thermophilic Campylobacter diversity [41]. Alterations in genetic make up of microorganisms could also be due to mutations, which may occur spontaneously in normal biological life.

A small proportion of $100 \%$ similar band patterns among C. jejuni (6.1\%) and C. coli isolates (5.3\%) from humans and chickens was observed implying that the Campylobacter were shared between humans and chickens in Morogoro Municipality. Previous studies in different parts of the world reported similarity among thermophilic Campylobacter isolates from human and chickens [2, 42, 43]. In Poland, cluster analysis of RAPD patterns from $115 \mathrm{Cam}$ pylobacter isolates from chickens and 80 from children revealed that six human $C$. coli isolates were identical to chicken isolates [43]. In Barbados, the OPA 11 fingerprinting of one C. jejuni and five C. coli isolates from human were identical to one $C$. jejuni and five $C$. coli from chicken meat, respectively [2]. In Canada, macrorestriction profiles of approximately $20 \%$ of human Campylobacter isolates were genetically related to genotypes found in poultry [42].

\section{Conclusions}

Thermophilic Campylobacter infection is prevalent both in children less than 5 years of age and chickens in Morogoro Municipality, Tanzania. Campylobacter jejuni is the leading cause of Campylobacter infections in children and chicken followed by $C$. coli while C. lari was not isolated. Both $C$. jejuni and C. coli isolates from humans and chickens showed high genetic diversity with only $6 \%$ of C. jejuni and $5 \%$ of C. coli from the two hosts being genetically similar (100\%). These thermophilic bacteria were most likely shared between children and chicken populations under this study in Morogoro Municipality. More genetic and epidemiological studies are recommended in Tanzania and elsewhere in the world to further explore genetic relatedness among thermophilic Campylobacter isolates from humans and both domestic and wild animals especially those at a close proximity to humans in day-to-day life in Tanzania.

\section{Abbreviations}

BTC: Belgian Technical Cooperation; NIMR: National Institute for Medical Research in Tanzania; NVH: Norges veterinærhøgskole (Norwegian School of Veteinary Science); OPD: Outpatient Department; PANTIL: Programme for Agriculture and Natural Resource Transformation for Improved Livelihood; PCR: Polymerase chain reaction; RAPD: Random amplified polymorphic DNA; SUA: Sokoine University of Agriculture; TANAPA: Tanzania National Parks

\section{Acknowledgements}

We acknowledge the financial support provided by BTC and Programme for Agriculture and Natural Resource Transformation for Improved Livelihood (PANTIL). Smooth cooperation received from Morogoro Municipal Council, laboratory technicians at Sokoine University of Agriculture, health facilities in Morogoro Municipality, patients and their parents/guardians is highly acknowledged. We are very much grateful for good cooperation and technical assistance we got from colleagues working with the Norwegian School of Veterinary Science (NVH) namely Prof. Martha Ulvund, Prof. Lars Olav Eik, Prof. Eistein Skjerve and Ms Hanna Jorgansen.

\section{Funding}

This study was funded by the BTC and extra costs for molecular biology analysis were covered by cordial assistance from Prof Rudovick R. Kazwala and Prof. Martha J. Ulvund of SUA and Centre for Small Ruminant Research of the NVH. Also funding from PANTIL facilitated travel to the NHV in Norway where molecular biology analysis was carried out.

\section{Availability of data and materials}

The datasets used and/or analyzed during the current study available from the corresponding author on reasonable request.

\section{Authors' contributions}

ISC designed the study in cooperation with RRK and HEN, did field sampling of chickens and collected human samples from the health facilities, laboratory and data analysis and wrote the manuscript. RRK, RHM and HEN provided technical advice during all phases of the study and critically reviewed the manuscript. All authors read and approved the final manuscript.

\section{Authors' information}

ISC is Wildlife Veterinarian working with Tanzania National Parks (TANAPA) did Bachelor and then of Veterinary Medicine (BVM and MVM) at SUA. He is currently doing a PhD student at the Department of Veterinary Medicine and Public Health, College of Veterinary and Medical Sciences (CVMS) of the Sokoine University of Agriculture (SUA) in Morogoro, Tanzania. RRK, RHM and HEN have been working as Professors/lectures cum Veterinarians for quite some time at the same department and college. 


\section{Competing interests}

The authors declare that they have no competing interests.

\section{Consent for publication}

Not applicable.

\section{Ethical approval and consent to participate}

The ethical clearance (NIMR/HQ/R.8a/Nol IX/303) granted by National Institute for Medical Research (NIMR) in Tanzania enabled undertaking of the current study and study chickens were handled and sampled in line with the Veterinary Act 2003. Prior to enrolment and sampling, purpose and importance of this study was explained and consent was obtained from each of participant (parents/guardians of children under 5 years on their behalf and chicken owners). Participation in this study was voluntary with strict confidentiality of information, freedom to stop participating at any time and regular feedbacks were given to the responsible medical staff at the study health facilities to help them rendering proper treatment to the patients.

\section{Author details}

${ }^{1}$ Tanzania National Parks (Serengeti), P. O. Box 3134, Arusha, Tanzania. ${ }^{2}$ Department of Veterinary Medicine and Public Health, Sokoine University of Agriculture, College of Veterinary and Medical Sciences, P. O. Box 3021, Morogoro, Tanzania.

\section{Received: 10 November 2016 Accepted: 14 November 2016}

Published online: 21 November 2016

\section{References}

1. Nachamkin I, Blaser MJ. Campylobacteriosis. 2nd ed. Washington: American Society for Microbiology; 2000

2. Workman SN, Mathison GE, Lavoie MC. Pet dogs and chicken meat as reservoirs of campylobacter spp. In Barbados. J Clinic Microbiol. 2005;43:2642-50.

3. Mdegela RH, Nonga HE, Ngowi HA, Kazwala RR. Prevalence of thermophilic campylobacter infection in humans, chickens and Crows in Morogoro, Tanzania. J Vet Med. 2006;B 53:116-21.

4. Altekruse SF, Stern NJ, Fields PI, Swedlow DL. Campylobacter jejuni an emerging foodborne pathogen. Emerg Infect Dis. 1999;5:28-35.

5. Rao MR, Naficy AB, Savarino SJ, Abu-Elyazeed R, Wierzba TF, Peruski LF. Pathogenicity and convalescent excretion of Campylobacter in rural Egyptian children. Am J Epidemiol. 2001;154:166-73.

6. Ali AM, Qureshi AH, Rafi S, Roshan E, Khan I, Malik AM, Shahid SA. Frequency of Campylobacter jejuni in Diarrhoea/Dysentery in Children in Rawalpindi and Islamabad. J Pakist Med Assoc. 2003:53:11.

7. Rani R, Pramanik AK, Das U. Role of exposure to domestic animals in the etiology of campylobacter enteritis in children of rural community. Indian Vet J. 2004:81:971-3.

8. Kusiluka LJM, Karimuribo ED, Mdegela RH, Luoga EJ, Munishi PKT, Mlozi MRS, Kambarage DM. Prevalence and impact of water-borne zoonotic pathogens in water, cattle and humans in selected villages in Dodoma Rural and Bagamoyo districts, Tanzania. Phys Chem Earth. 2005;30:818-25.

9. Nonga HE. Epidemiology of thermophilic Campylobacter in humans, chickens and water in Morogoro, Tanzania. A dissertation for award of MVM degree. Morogoro: Sokoine University of Agriculture; 2005. p. 1-118.

10. Nonga HE, Muhairwa AP. Prevalence and Antibiotic Susceptibility of Thermophilic Campylobacter Isolates from Free-Range Ducks in Morogoro Municipality, Tanzania. Trop Anim Heal and Prod. 2009;42 Suppl 2:165-72.

11. Nonga HE, Karimuribo ED, Patrick S. Occurrences of Thermophilic Campylobacter in Cattle Slaughtered at Morogoro Municipal Abattoir, Tanzania. Trop Anim Heal and Prod. 2009;42 Suppl 1:73-8.

12. Mdegela RH, Kibona L, Jacob P, Nonga HE. Occurrences of thermophilic Campylobacter in pigs slaughtered at Morogoro slaughter slabs, Tanzania. Trop Anim Heal Prod. 2011;43:83-7.

13. Kurwijila RL, Mdoe N, Nyange DN, Auerbock RM, Malya HN. Assessment of fresh milk and milk products and consumption in Dar es Salaam, Report to the Austro Project Association, Dar es Salaam. 1995. p. 54

14. Brown $\mathrm{H}$. Assessment of microbial quality of raw cow's milk and antimicrobial susceptibility of selected milk-borne bacteria in Kilosa and Mvomero districts, Tanzania. Dissertation for Award of MSc. Degree of Public Health and Food Safety. Morogoro: Sokoine University of Agriculture; 2014. p. 1-95.
15. Swai ES, Schoonman L, Daborn C. Knowledge and attitude towards zoonoses among animal health workers and livestock keepers in Arusha and Tanga, Tanzania. Tanzania J Heal Res. 2010;4:205-9.

16. Kunda M. A study on gender knowledge and risk factors associated with zoonotic diseases with reference to leptospirosis, Q-fever and brucellosis in northern Tanzania. Dissertation for Award of MSc. Degree of Public Health and Food Safety. Morogoro: Sokoine University of Agriculture; 2014. p. 1-95.

17. Mushi D, Denis B, Alexander KTK, Robert LM, Kirschner KB, Andreas HF. Sanitary inspection of wells using risk-of-contamination scoring indicates a high predictive ability for bacterial faecal pollution in the peri-urban tropical lowlands of Dar es Salaam, Tanzania. J Water Heal. 2012;10 Suppl 2:236-43.

18 Kakulu RK. Diarrhoea among under-five children and household water treatment and safe storage factors in Mkuranga district, Tanzania. Dissertation for Award of MSc. Degree of Applied Epidemiology. Dar es Salaam: Muhimbili University of Health and Allied Sciences; 2012. p. 1-90.

19 Mattioli MC, Pickering AJ, Gilsdorf RJ, Davis J, Boehm AB. Hands water as vectors of diarrheal pathogens in Bagamoyo, Tanzania. Env Sc Tech. 2013;47 Suppl 1:355-63.

20 Jiwa SFH, Mdegela RH, Kazwala RR. Epidemiology of thermophilic Campylobacter species in apparently healthy domestic ducks kept as free range without veterinary inputs in Morogoro Municipality. Tanz Vet J. 1997;17:73-81.

21. Stepniak E, Zagalska M, Switonski M. Use of RAPD technique in evolution studies of four species in the family Canidae. J Appl Genetics. 2002;43:489-99.

22. Hernandez J, Fayos A, Ferrus MA, Owen RJ. Random amplified polymorphic DNA fingerprinting of Campylobacter jejuni and C. coli isolated from human faeces, seawater and poultry products. Res Microbiol. Paris: Elsevier; 1995; 146:685-96.

23. Thrusfield M. Veterinary Epidemiology. 2nd ed. Blackwell; 1995; p.483.

24 Lindblom GB, Ahren C, Changalucha J, Gabone R, Kaijser B, Nilsson LA, Sjogren E, Svennerholm AM, Temu M. Campylobacter jejuni/coli and enterotoxigenic Escherichia coli (ETEC) in faeces from children and adults in Tanzania. Scand J Infect Dis. 1995;27:589-93.

25. Miwa N, Takegahara Y, Terai K, Kato H, Takeuchi T. Campylobacter jejuni contamination on broiler carcasses of $C$. jejuni-negative flocks during processing in a Japanese slaughterhouse. Int Food Microbiol. 2003:84:105-9.

26. Coulombier D, Fagan R, Hathcock L, Smith C. Epi Info 6 version 6.04. A word processing, database and statistical program for public health. Delaware: Centers for Disease Control and Prevention; 2001.

27 United Republic of Tanzania (URT) Ministry of Health. Policy implications of adult morbidity and mortality: End of Phase 1 Report. Dar es Salaam: Ministry of Health, United Republic of Tanzania; 1997.

28. Trachoo N. Campylobacter jejuni: An emerging pathogen. Sonklanakarin J Sci Technol. 2003;25:141-57.

29. Marquis GS, Ventua G, Gilamn RH, Porras E, Miranda E, Carbajal L, Pentafiel M. Faecal contamination of shanty town toddlers in households noncorralled poultry, Lima, Peru. Am J Public Health. 1990:80:146-9.

30. Coker AO, Adefeso AO. The changing patterns of Campylobacter jejuni/coli in Lagos Nigeria after 10 years. E Afric Med J. 1994;71:437-40.

31 Albert MJ, Faruque AS, Faruqe SM, Sack RB, Mahalanabis D. Case control study of enteropathogens associated with childhood diarrhoea in Dhaka, Bangladesh. J Clinic Microbiol. 1999;37:345-64.

32 Banfi E, Cinco M, Zabucchi G. Phagocytosis of Campylobacter jejuni and C. coli by peritonial macrophages. J Gen Microbiol. 1986;132:2409-12.

33 Taylor DN, Echeverria P, Pitarangsi C, Seriwatana J, Bodhidatta L, Blaser MJ. Influence of strain characteristics and immunity on the epidemiology of Campylobacter infections in Thailand. J Clinic Microbiol. 1998;26:863-8.

34 Engvall A, Bergovist A, Sandstedt K, Danielsson-Tham ML. Colonization of broiler with Campylobacter in conventional broiler chicken flocks. Acta Vet Scand. 1986;27:540-7.

35. Kazwala RR, Collins JD, Hannan J. The establishment and spread of experimental Campylobacter jejuni infections in young chickens. Prev Vet Med. 1992:13:19-26.

36. Saleha AA, Mead GC, Ibrahim AL. Campylobacter jejuni in poultry production and processing in relation to public health. World Poultry Sci J. 1998:54:50-7.

37 Saleha AA. Epidemiological study on the colonization of chickens with Campylobacter in Broiler Farms in Malaysia: Possible Risk and Management Factors. Int J Poultry Sci. 2004;3:129-34.

38 Byrne CM, Clyne M, Bourke B. Campylobacter jejuni adhere to and invade chicken intestinal epithelial cells in vitro. Microbiol. 2007;153:561-9. 
39 Jacob P, Mdegela RH, Nonga HE. Comparison of Cape Town and Skirrow's protocols in isolation of Campylobacter from humans and broilers in Morogoro, Tanzania. Trop Anim Heal Prod. 2011;43 Suppl 5:1007-13.

40 Kazwala RR, Collins JD, Hanna J, Crinion RAP, O'Mahony H. Factors responsible for introduction and spread of Campylobacter jejuni in commercial poultry production. Vet Rec. 1990;126:305-6.

41 Wassenaar TM, On SLW, Meinersmann RJ. Genotyping and the consequences of genetic instability. In: Nachamkin I, Blaser MJ, editors. Campylobacter. 2nd ed. Washington, DC: ASM Press; 2000. p. 369-80.

42 Nadeau E, Messier S, Quessy S. Prevalence and comparison of genetic profiles of Campylobacter strains isolated from poultry and sporadic cases of campylobacteriosis in humans. J Food Protect. 2002;65:73-8.

43. Rozyneck E, Dzierzanowska-Fangrat K, Jozwiak P, Popowski J., Korsak, D, Dzierzanowska D. Poultry as a potential source of Campylobacter jejuni and Campylobacter coli infections in children in Poland. In: 16th

EuropeanCongress of Clinical Microbiology and Infectious Diseases. Nice: Blackwell Publishing; 2006.

\section{Submit your next manuscript to BioMed Central} and we will help you at every step:

- We accept pre-submission inquiries

- Our selector tool helps you to find the most relevant journal

- We provide round the clock customer support

- Convenient online submission

- Thorough peer review

- Inclusion in PubMed and all major indexing services

- Maximum visibility for your research

Submit your manuscript at www.biomedcentral.com/submit 